\title{
Memoria política y relatos de infancia: La casa de los conejos, de Laura Alcoba, y ¿Quién te creés que sos?, de Ángela Urondo Raboy
}

\section{Political memories and childhood narratives: Laura Alcoba's, La casa de los conejos (The house of the rabbits), and Ángela Urondo Raboy's ¿Quién the creés que sos? (Who do you think you are?)}

Silvia Cárcamo

Universidade Federal do Rio de Janeiro (UFRJ), Rio de Janeiro, Rio de Janeiro, Brasil. silviacarcamo@globo.com

Resumen: Situamos los relatos de infancia La casa de los conejos, de


en la tradición reciente pero obstinada de la narrativa argentina que incursiona en historias de la militancia política de los años setenta. Esas narrativas de infancia proponen un trabajo arqueológico sobre el lenguaje de esa década a partir de la complejidad que supone la doble voz, infantil y adulta, que se expresa en el relato. Teniendo en cuenta las visiones de Gaston Bachelard y de Gilles Deleuze prestamos atención al sistema imagético de la infancia que estas obras construyen. Notamos que la vuelta a la lengua infantil y al lenguaje de los padres cuestiona la heroización del militante, sin renunciar por ello a la memoria. Las obras estudiadas, que muestran nuevos modos de concebir la política, también pueden ser analizadas en el contexto del debate sobre la "resistencia a la memoria" (Andreas Huyssen) y la "memoria insatisfecha (Nelly Richard). Palabras-clave: relatos de infancia; literatura argentina actual; memoria. 
Abstract: We situate the childhood narratives by Laura Alcoba and Ángela Urondo Raboy (La casa de los conejos and ¿Quién te creés que sos?, respectively) among the late but obstinate tradition of Argentinian narratives of political engagement in the 1970's. These childhood narratives intent to do archeological research on the language of that decade taking into consideration the complexity of the double speech register - infant and adult - represented in the narratives. Following Gaston Bachelard and Gilles Deleuze, we have paid attention to the imagetic system of childhood that those works construct. We have also observed that the return to the children's language and to the language of the parents questions the monumentalization of political engagement, without at the same time discarding memory. These works, which show new ways of conceiving political engagement, are also analyzed in the context of the debate about "resistance to memory" (Andreas Huyssen) and "dissatisfied memory" (Nelly Richard).

Keywords: childhood narratives; contemporary Argentinian literature; memory.

Recebido em 19 de dezembro de 2014.

Aprovado em 24 de abril de 2015.

El núcleo narrativo vinculado a la experiencia política de los años setenta no cesa de manifestar su condición proliferante en la literatura argentina de las últimas décadas. El carácter polémico de dicho núcleo se agudiza más aún cuando el mismo asume críticamente los relatos de la militancia de la época. En su despliegue se exponen diferencias que permanecen todavía vivas en el debate social sobre un período político altamente frecuentado no sólo por la literatura sino también por otros discursos públicos.

Lo vemos emerger de modo sorpresivo y momentáneo en el mundo literario de Juan José Saer, desde Glosa (1988) a La grande (2005), o constituirse en la recreación de una obsesión pasada en Alan Pauls, con Historia del pelo (2011). El ensayo, por otro lado, señaló los aspectos más problemáticos de las interpretaciones, como lo demuestran las múltiples intervenciones críticas de Beatriz Sarlo, José Pablo Feinmann y Leonor Arfuch, protagonistas centrales en el debate intelectual argentino de los últimos años. 
José Pablo Feinmann, distanciándose de la ironía de Alan Pauls o de la sutileza artística de Saer, fue a buscar en el guevarismo el origen inmediato de las prácticas de la militancia de los años setenta. En algunos escritos y particularmente en La sangre derramada. Ensayo sobre la violencia política (1999) ${ }^{1}$ acusó a esa militancia de inspirarse en la figura heroica del Che Guevara para legitimar la violencia armada.

Frente a la abundancia de expresiones testimoniales y de ficcionalizaciones en los campos de la literatura y del cine, tanto Beatriz Sarlo como Leonor subrayaron la emergencia inevitable de cuestiones éticas en las perspectivas colocadas en juego por esos relatos.

Como parte de ese núcleo narrativo al que hicimos referencia adquieren relieve en los últimos años los relatos de infancia que nos interesan. Teniendo en cuenta la problematización crítica de las cuestiones relacionadas a la memoria, a la revisión de las experiencias políticas de los años setenta y a sus relatos posteriores, abordamos la novela $L a$ casa de los conejos (2008), de Laura Alcoba y la obra híbrida y catártica ¿Quién te creés que sos?(2012), de Ángela Urondo Raboy.

Las autoras eran niñas en los años setenta y escribieron, ya de adultas, relatos autobiográficos de infancia. Afectadas por la violencia vivida en los años setenta y por las opciones políticas de sus padres militantes, ellas continúan indagando a respecto de ese pasado.

En "autografemas" de infancia, para usar la expresión de Barthes (1971), Laura Alcoba y Ángela Urondo Raboy desarrollan singulares estrategias de autofiguración, alejándose de las formas canónicas del testimonio. Sostenemos que la ficcionalización y la apuesta estética que consiste en rememorar, e incluso en imaginar voces infantiles, se relacionan al desarrollo de nuevas reflexiones sobre el pasado traumático y también sobre los modos políticos de una época. Ambas obras representarían la expresión de una "memoria insatisfecha" (Nelly Richard), como analizó Jordana Blejmar, a respecto de Diario de una princesa montonera, otro relato de niña, de Mariana Eva Pérez. Postulamos que esas memorias de infancia pueden ser leídas como indicios de nuevas subjetividades que cuestionan las concepciones tradicionales de la participación política.

Lo que sin duda merece mayor relieve es el hecho de que ambas obras coincidan en la exploración profunda del lenguaje de la infancia y del lenguaje de la generación de sus padres, que bien podríamos llamar

\footnotetext{
${ }^{1}$ Ver estudio de Rita De Grandis (2006).
} 
de arqueológica. Laura Alcoba y Ángela Urondo Raboy se refieren a las niñas reales y a sus experiencias en tiempos de violencia, pero sus textos manifiestan, por el trabajo con el lenguaje, la infancia que permanece siempre en el adulto, si estamos de acuerdo con lo postulado, entre otros, por Gaston Bachelard o Gilles Deleuze. Por eso no nos parece insignificante la construcción de un sistema imagético conectado con las visiones de la infancia.

La recuperación de las experiencias de niñas también cuestionan la entronización acrítica de los héroes, sin renunciar, por ello, a la memoria. Los episodios violentos y traumáticos pertenecen a la historia de una infancia efectivamente vivida, y al mismo tiempo describen una elaboración mítica, como lo demuestra la incesante figura de la orfandad que delinean los relatos. Un adulto que siente el vacío de la falta de los padres estaría manifestando al niño que todavía es; el hombre que vacila en el lenguaje estaría volviendo al lenguaje inseguro y creativo de los primeros años, a los balbuceos iniciales, como propone Deleuze. Trabajar el lenguaje para recuperar la infancia forma parte de la propuesta de escritura de Laura Alcoba y de Angela Urondo Rajoy.

\section{La casa de los conejos: imágenes, mudez y secretos}

Cualquier interpretación de la novela de Laura Alcoba supone considerar aspectos relacionados a la historia personal de la propia autora, marcada por la escisión entre un antes y un después de la experiencia de su infancia en Argentina.

En el breve artículo titulado "La mirada de la niña. Sobre $L a$ casa de los conejos de Laura Alcoba", Mariela Peller ya señaló que el relato de la vida cotidiana de un grupo de militantes, desde la perspectiva de una niña lleva a discutir la exposición de la infancia en el contexto de violencia política. En el orden formal se destacan "los vínculos que la novela mantiene con el relato testimonial. Porque si bien el registro es claramente ficcional, el lector sabe -porque la novela se encarga de crear ese pacto de lectura con él-, que los datos que se narran tienen asidero en la realidad" (2009, p.1) Por su parte, Anna Forné, señala la ruptura con el testimonio canónico y, basada en la noción de Nelly Richard de "memoria insatisfecha", entiende que la novela representa un cuestionamiento a las memorias oficiales o sedimentadas. Teniendo en cuenta que la narradora se llama Laura, como la autora, Forné señala el 
juego autoficcional, que supone, como sabemos, el consecuente efecto de tensión entre la fabulación y la no fabulación. En el caso de la novela de Laura Alcoba obliga a tener en cuenta informaciones referidas a las circunstancias de la escritura y la circulación de la obra. Argentina fue el lugar en el que acontecieron los sucesos; Francia, el ámbito de la elaboración de La casa de los conejos o de Mànege. El primero es el título de la edición publicada en Buenos Aires en 2008, con traducción del Francés a cargo del escritor argentino Leopoldo Brizuela. La novela fue escrita originalmente en lengua francesa, y publicada en Francia por la editorial Gallimard en 2007, bajo el título de Màneges. Petite histoire argentine.

Los títulos, aunque diferentes en Francés y en Español, coinciden en la alusión a imágenes vinculadas a la infancia traumática. En Francés, la "calesita" ("màneges") de la plaza a la que era llevada la niña en operaciones clandestinas para encontrar a los abuelos, pero la polisemia de la palabra hace pensar también en "manipulación"; en Español, en cambio, remite a la casa donde finalmente sucederá la masacre.

La llamada "Casa de los Conejos" se ubicaba en la ciudad de La Plata en la que vivieron, entre 1975 y 1976, la niña Laura con su madre y otros militantes del movimiento peronista Montoneros. Allí funcionaba, en una especie de bunker, disimulado mediante un sofisticado sistema, una imprenta clandestina. En ella se imprimía el órgano de difusión "Evita Montonera", bajo la responsabilidad de la madre de Laura, cuyo marido, el padre de la niña, estaba preso desde antes del golpe de Estado de marzo de 1976. Para no levantar sospechas de los vecinos, instalan en la casa un criadero de conejos.

El funcionamiento de la casa, los movimientos de los habitantes y la arriesgada vida cotidiana del grupo son registrados a partir de la mirada de la niña de siete años. Clandestinizada como consecuencia del compromiso militante de sus padres, con nombre falso, la niña es retirada de la escuela e instruida para vivir la vida de los adultos dedicados integralmente a las actividades de la militancia política.

Una fuente de tensión de la novela deriva, en parte, como observó Anna Forné, de la propuesta de fabulación de una historia verdadera. La otra fuente de complejidad radica en la alternancia de dos voces: la de la Laura adulta y la de la Laura niña. La niña, más que una voz hablante es una mirada que registra. En esa diferenciación, altamente compleja, basaremos los comentarios sobre la visión de la infancia en la novela. 
Al comienzo, una primera persona, presentada con el nombre de la autora, declara que el estímulo para la escritura de la obra surgió en ocasión del viaje de visita a Argentina en el 2003. La novela se presenta como una acción de homenaje a la memoria de Diana Teruggi, a quien el libro está dedicado y a quien identifica explícitamente en el vocativo:

Voy a evocar al fin toda aquella locura argentina, todos aquellos seres arrebatados por la violencia. Me he decidido, porque muy a menudo pienso en los muertos, pero también porque ahora sé que no hay que olvidarse de los vivos. Más aún: estoy convencida de que es imprescindible pensar en ellos. Esforzarse por hacerles, también a ellos, un lugar. Esto es lo que he tardado tanto en comprender, Diana. (ALCOBA, 2012, p. 12)

La Laura adulta vuelve a evocarla en las últimas páginas de la novela, ahora vinculada a la memoria de la niña Clara Anahí, la hija expropiada de Diana Teruggi: "Clara Anahí vive en alguna parte. Ella lleva sin duda otro nombre. Ignora probablemente quiénes fueron sus padres y cómo es que murieron. Pero estoy segura, Diana, que tiene tu sonrisa luminosa, tu fuerza y tu belleza." (ALCOBA, 2012, p. 134). En ese final, y en el comienzo, se manifiesta la lejanía respecto a los hechos sucedidos, aunque el vocativo indique la intención de traer a la escena la presencia fantasmal de Diana. En el resto de la novela, en cambio, desde la posición enunciativa de la niña, la narración en tiempo presente es la propia de la modalidad del diario personal, por el cual Laura se presenta de la siguiente manera:

tengo siete años pero todo el mundo dice que hablo y razono como una persona mayor. Los hace reír que sepa el nombre de Firmenich, el jefe de los Montoneros, e incluso la letra de la marcha de la Juventud Peronista, de memoria. A mí ya me explicaron todo. Yo he comprendido y voy a obedecer. No voy a decir nada. Ni aunque vengan también a casa y me hagan daño." (ALCOBA, 2010, p. 18)

En la secuencia anterior al fragmento que acabamos de citar, la niña cuenta el relato que escuchó de los adultos sobre militantes que fueron presos a causa de un bebé, quien señaló un cuadro detrás del cual había un escondite. La niña narradora concluye "Todos están presos ahora, por culpa del niño que apenas sabía hablar” (ALCOBA, 2010, p.17) 
Los niños deben compartir el compromiso político de los adultos, pero lo hacen de una manera imperfecta; en consecuencia, recae sobre ellos la sospecha de la incapacidad, por la propia naturaleza, de actuar como los militantes. Son, por lo tanto, objeto de la desconfianza de los adultos.

La Laura niña y la Laura adulta no son idénticas. Esa diferencial instala posiciones temporales colocadas en tensión. Una de esas temporalidades corresponde al registro de la niña. La otra, en cambio, establece la distancia tensa entre el pasado infantil y el tiempo presente de la adulta. La primera narradora no juzga; la segunda, en cambio, no puede evitar el juicio a sus padres y la recuperación de sensaciones desagradables.

La consulta al archivo, formando parte de la novela, se suma a la experiencia vivida, a la memoria. Pocos meses después de la salida de Laura y de su madre de La Plata y de Argentina, la "Casa de los conejos" fue bombardeada en una operación espectacular del Ejército, en el cual fueron asesinados los militantes que se encontraban en la casa. Allí murió Diana Teruggi, personaje de la historia infantil a quien se dedica la novela, y allí desapareció Clara Anahí, hija de Diana y uno de los niños expropiados en Argentina.

La narradora adulta reconstruye en la escritura esa Argentina de los años setenta para emprender lo que la narradora niña estaría imposibilitada de realizar: un trabajo arqueológico sobre imágenes, gestos, lenguajes, sensaciones de otra época que quedaron en la memoria como restos. Se despliega en la novela de Laura Alcoba la investigación arqueológica sobre el lenguaje de la militancia setentista y el trabajo de archivo sobre lo no vivido que completa la historia vivida. Memoria e Historia parecen precisarse mutuamente.

En uno de los capítulos más interesantes, la narradora adulta relata sus indagaciones filológicas sobre la palabra "embute", grabada en la memoria desde los tiempos vividos en la "Casa de los Conejos". La búsqueda en diccionarios y textos la lleva a la sorprendente comprobación de que esa palabra usada por militantes -la imprenta de la "Casa de los conejos" era un "embute"-había desaparecido de la lengua o correspondía a otros significados distanciados del sentido que ella conocía.

La palabra permaneció en la memoria como resto, como ruina, y emerge como anacronismo lingüístico unas décadas más tarde. La "Casa de los conejos" permanece también como una ruina, en la calle 30 de la ciudad de La Plata. Esa ruina, con vestigios del bombardeo, forma parte 
de la memoria del presente, lugar de rememoraciones y celebración de un episodio traumático de la historia argentina. ${ }^{2}$

La atención concentrada en el lenguaje, que los conduce a interrogar la lengua secreta de los padres, los usos particulares de las palabras, de los dichos, consignas y estilos propios de la política argentina de los años sesenta y setenta, también son marcas relevantes de la poética de la memoria de otros escritores que vivieron en la infancia historias traumáticas, como Ángela Urondo Raboy y Nicolás Prividera. ${ }^{3}$ En algunos casos, como es más evidente en la primera, el trabajo arqueológico se realiza desde una inevitable, orgullosa y sentida orfandad.

Particularmente impresionante resulta la casi inexistencia del registro de intervenciones de habla espontánea de la niña en La casa de los conejos. Ella registra minuciosamente: recibe órdenes, acepta pedidos, escucha los comentarios de los adultos, ve y observa con atención cada lugar, cada movimiento. Significativamente, Laura no habla: son los otros los que se dirigen a la niña. A modo de comprobación, presentamos algunos ejemplos:

Mi abuelo me comunica que mi madre acaba de llamar por teléfono (p. 25)

Mi padre pidió que le escriba todas las semanas. Me dijo que leerme, claro, le ayudará" (p.26)

Mi madre de pelo rojo avanza a paso firme, sin decirme palabra. Entre ella y la muñeca, yo sigo su impulso, y no me atrevo a romper el silencio" (p. 35)

Volvemos a la cocina donde mi madre y la señora se juntan, contra la pared, a discutir algo" (p. 36)

Yo juego un poco con ellos, juegos a los que no estoy nada habituada. Entre nosotros, jamás hablamos de lo que está pasando, ni de la clandestinidad (p. 42)

\footnotetext{
${ }^{2}$ La "Casa Mariani-Teruggi"es monumento histórico nacional, dirigido por Chicha Mariani, suegra de Diana y madre de Daniel Mariani, esposo de Diana. Ver $<\mathrm{http}$ // procesosconstructivos.files.wordpress.com/2012/05/casa-mariani-teruggi.pdf $>$

${ }^{3}$ Prividera dirigió el documental "M", sobre la desaparición de su madre, en marzo de 1976. Más recientemente, en "Los padres de la patria" (2012) coloca como centro de la película los violentos y contradictorios discursos fundacionales de la nación. En Restos de restos incursiona en los enunciados enigmáticos oídos en su infancia.
} 
-Lo lamento, pero tengo que empezar todo desde el principio. Explicale vos a la nena...!y que se calle, carajo! (p. 44)

-¡No jugués más a eso! ¿Me entendiste?

Yo bajo la cabeza y me pongo a llorar" (p. 61)

Entonces mi abuela empezó a hablarme a mí, que estaba a sus espaldas (p. 86)

Yo no consigo hablar. Miro al ingeniero espantada. (p. 100)

Yo todavía era incapaz de decir palabra. Felizmente, Diana habló por mí.

Muda todavía, yo asiento con un movimiento de cabeza. (p. 109)

- ¿Viste esa mujer? La torturaron, pero no cantó. Le hicieron cosas horribles, sabés, cosas que no son para contarle a una nena como vos. Pero no abrió la boca. Aguantó todo sin decir una palabra.

Yo no insistí en saber en qué consistían esas "cosas". Yo también sé callarme, sí. (p. 111)

Pero tal vez no sea tan clara la existencia de dos lenguajes que identificarían, con precisa nitidez, dos momentos de la vida de Laura. El habla de la niña se muestra irremediablemente contaminada por la experiencia posterior, por la vivencia y por el aprendizaje del sujeto adulto, del mismo modo como en su relato adulto aparece la voz de la niña. Preferir "mi madre" en lugar de "mi mamá", conocer una palabra refinada en el Español del Río de la Plata como "postigo" muestran la interferencia de las modalidades lingüísticas de la adulta en la voz infantil.

Para la Laura adulta - o más precisamente, para la construcción textual de la Laura que está escribiendo la novela -, el recuerdo del pasado llevaba a ordenar los hechos, para lo cual antes era preciso transformar "en palabras las imágenes, los momentos y los retazos de conversaciones"'(2012, p. 47). Con admirable claridad, Bachelard ayuda a aproximarnos a ese proceso complejo cuando escribe que "La memoria es un campo de ruinas psicológicas, un amontonado de recuerdos. Toda nuestra infancia está por ser reimaginada." (1988, p.94). El desafío de Laura Alcoba consiste en situarse en el campo de la memoria con el lenguaje de la literatura, es decir, de la imaginación, y ensayar con él la distancia crítica. 


\section{¿Quién te creés que sos?: figuras, palabras y juegos de infancia.}

Ángela Urondo Raboy creció ignorando la identidad de sus padres, el poeta Francisco "Paco" Urondo y la periodista Alicia Raboy. Sólo de adulta, conoció los episodios ocurridos en Mendoza en 1976, cuando su padre, cercado por el aparato represivo, tomó una pastilla de cianuro para no ser preso con vida (o, según otra versión, la defendida por Angela, fue capturado vivo y después asesinado). En ese mismo enfrentamiento, Alicia Raboy fue secuestrada y permanece hasta hoy desaparecida. Ángela, que estaba con su madre y contaba con apenas once meses, fue dejada en un Centro clandestino de detención, llevada después a un orfanato y finalmente adoptada por familiares de la madre. A pesar de los lazos familiares, la pareja adoptante impone un extraño silencio sobre la vida de los padres biológicos. Cuando ya es una joven, Ángela entra en crisis, emprende la búsqueda de su identidad y promueve la "desadopción", en un proceso que la conduce simultáneamente a la participación política y a la expresión artística.

Del libro de Ángela titulado ¿Quién te creés que sos?, fue dicho que "es una combinación de testimonio, diario íntimo y biografía" (ENRIQUEZ, 2013, p. 1). Como en el caso de La casa de los conejos, y por las mismas razones, la lectura de los textos de Ángela no admite ignorar la vida de la autora. Por ello, los géneros del testimonio, del diario íntimo y de la biografía son casi inevitables. Ángela escribe en sus blogs, Pedacitos de Angela, Urondo e Infancia y Dictadura, que preceden al libro, para contar su historia, profundamente signada por la historia de la participación de sus padres en la lucha política de los años setenta. Ángela cultiva la exposición de su historia y de su imagen, apareciendo en la televisión o prestándose a que otros cuenten su historia, como sucede en el libro En mi nombre. Historias de identidades restituidas (2014), de Ángela Pradelli.

En su relato de infancia se reconoce la conciencia de la adulta que debe imaginar a la niña que ella fue para llenar un vacío que identifica en el origen. Ángela precisa nombrar y restablecer una relación con los padres de los cuales no conserva ninguna memoria. La negación de la memoria como decisión familiar redundó en la falta de voces y de imágenes, de modo que el trabajo de escritura será también el de la recuperación de las imágenes y de las voces negadas. Antes, y como una obsesión, debe inventar los recuerdos del breve y agitado período 
en el que vivió con sus padres. Se exige a sí misma imaginar un modo de dirigirse a ellos, lo cual implica elaborar la lengua de la infancia. Como también fue escamoteado el círculo de amistades de Paco Urondo y de Alicia Raboy, donde militancia y trabajo se identificaban, la autora propone recuperar el contexto humano negado. Entre la investigación en búsqueda de voces y el sueño, la memoria de Ángela imagina y se manifiesta en ensoñaciones.

La elaboración de un universo imagético vinculado a la infancia se reconoce como estrategia de la autora adulta para rememorar imaginando. Cabe volver a la pergunta esencial de Leonor Arfuch, inspirada, a su vez, em indagações de Maurice Halbwachs:

La pregunta sobre "cómo usamos nuestras imágenes mentales del presente para reconstruir el pasado" obtendrá hoy sin duda diferentes respuestas, pero sin contrariar justamente esa focalización en el presente y esa cualidad social -aun la autobiográfica- que el autor destacara como constitutivas, así como el hecho evidente y no por eso menos perturbador de que sólo los individuos-y no los grupos, las instituciones, recuerdan. (ARFUCH, 2008, p.78)

No puede ignorarse el hecho de que Ángela actúa y escribe en un presente significado socialmente, y que ella no ignora modos contemporáneos de comunicación y expresión, como lo indica el hecho de que antes de la aparición en el libro, los textos circularan en los blogs de títulos significativos, conectados, a su vez, con otros blogs, como el "Diario de una princesa montonera", de Mariana Eva Pérez, otra hija de desaparecido. Para Jordana Blejmar ese blog de Mariana, que antecedió igualmente al libro del mismo título, publicado por la editorial "Capital Cultural", la misma que editó el libro de Ángela, introduce nuevas y singulares vías de circulación de la memoria:

Estas conexiones rizomáticas entre los blogs construyen un mapa de estéticas e inquietudes sobre la historia reciente y sus efectos en el presente, vinculadas a una memoria generacional, que circulan por fuera de espacios de intervención cultural y divulgación de memorias de más larga data como el cine y la literatura. (BLEJMAR, 2012) 
¿Quién te creés que sos? está concebido como conjunto de fragmentos que logra una sólida unidad gracias al trazado de redes. Los materiales dispersos se conectan entre sí, y simultáneamente, por la misma lógica relacional, los textos se abren a un territorio extratextual. Las conexiones internas y externas revelan la lógica del blog. Como sintetiza Blejman, los blogs tienen como característica esencial "el ser espacios de autorrepresentación y puestas en escena de un yo que esconde tanto como lo que dice mostrar" (BLEJMAN, 2012). Esa marca pasa del blog al libro. En el de Ángela se exhibe la trayectoria de la investigación emprendida por ella misma, cuyo momento culminante se revela en la última parte, compuesta de un texto único. Es la carta que Ángela dirige a sus padres usando un género casi anacrónico para su generación como lo es la carta personal, perto que sin embargo abunda en los blogs.

La expresión elegida para dirigirse a los padres en el encabezamiento de la carta ("Queridos papis") recupera la expresión infantil que evidentemente Angela nunca tuvo oportunidad de pronunciar. Uno de los trazos del lenguaje infantil de ¿Quién te creés que sos? consiste en las citas, sin comillas, incorporadas al discurso de la autora, de juegos verbales para niños, de restos de literatura infantil y juvenil, de canciones de cuna. Como vestigios de un lenguaje del pasado en el habla de la Ángela adulta, funcionan a modo de recursos para instalar el juego irónico. "Miguitas de pan en el camino" (p. 62) evoca la aterrorizante historia de Hansen y Gretel; "Serán felices y comerán perdices" (p.102) reitera el clásico final de los cuentos de hadas; "hubiera sido un buen final si taza, taza, cada uno se hubiese para casa" (p. 176), recupera versos de niños; "Espejo, espejito" (p. 199) alude a la madrasta mala del cuento; "María Santana" (p. 109), rememora una de las más conocidas canciones de cuna de la tradición católica, que Ángela conecta a su orfandad y a su niñera. "Annie, la huerfanita" (p. 111), "Heidi (p.110) provocan identificaciones basadas en las desventuras de personajes de la literatura infantil para niñas.

La composición del poema "Veo-Veo" se basa en la modificación irónica y distanciada del juego verbal infantil de la tradición hispánica, que consiste en identificar un objeto por su color: "Veo, veo/ ¿Qué ves?/ Una cosa/ ¿Qué cosa?/Maravillosa./¿De qué color?”. O poema recrea el juego: 
(Veo-Veo ¿qué ves?) / Con estos ojitos, veo a mis padres./ La lana del pullover de mamá, el bigote, las manos de papá./ Con estos ojos veo sonrisas, veo sol, veo ruta y veo montaña./ La casita de acá y la casita de allá./Con mis ojos veo amor, veo poesía. / Todo lo que vivo veo y deja en mí su huella./(Veo-Veo ¿Y ahora? ¿Qué veo?)/Veo miedo, veo rojo, veo ruido, veo carne./ Veo puertas, ventanas. Un pasillo con cubículos oscuros a los / costados./ Veo a mamá ahí, y no la veo más. /Veo acercarse de frente tubos largos de metal, hasta quedar / tan cerca de los ojos que los veo por dentro. (Una cosa imaravillosa! ¿De qué color?) Veo negro. (URONDO RABOY, 2012, p. 200)

Mientras en el juego infantil hay que identificar un objeto a la vista, el yo lírico de "Veo-Veo" propone una alteración para narrar la escena traumática da su infancia, y evocar, una vez más, a sus padres.

El sistema imagético de ¿Quién te creés que sos? insiste en dos figuras dominantes, ambas relacionadas a la infancia: el rompecabezas y el Álbum. Las tareas consisten en formar la figura de las partes del rompecabezas y de completar el álbum. La satisfacción llega cuando se encuentran las piezas, tal como Walter Benjamin (2007, p. 107) describió la vocación infantil por la colección. Ese ejercicio demanda la presencia de los otros, ya que no siendo tarea solitaria, supone antes complicidades y adhesiones. Las colaboraciones van registrándose en el libro, como la del primo de la madre, "Angelita: Soy Lucio, primo segundo de tu mamá. Para tu rompecabezas, yo te mando la imagen de tu mamá" (URONDO RABOY, 2012, p. 147). Como en el blog, la autora organiza las entradas y las voces de los otros proliferan: los escritos de Rodolfo Walsh y de Horacio Verbitsky sobre los últimos días de Paco Urondo, los comentarios de amigos y familiares de los padres, que van de lo íntimo y afectivo a lo político y a los informes de los procesos judiciales de las causas por violación de derechos humanos.

El álbum es figura central del poema "Incompleto", cuya primera estrofa expresa "A mi álbum/ le faltan un par de figuritas. / Pensé que las tenía todas, pero no / faltan unas viejas, del principio.” (2012, p. 196). Recordamos, a propósito, que Leonor Arfuch reflexiona sobre la noción de álbum en las manifestaciones artísticas contemporáneas, subrayando que 
si la propia idea de "álbum" remite a una estructura necesariamente discontinua, a la irrupción fragmentaria, a las fotos sueltas, mezcladas, incluso desconocidas, que han perdido su anclaje temporal preciso, su existencia supone no obstante la hilación de una historia, un "antes" y un “después”. (ARFUCH, 2008, p. 48)

Ángela busca recomponer la continuidad en su álbum de infancia. Él no puede ser encontrado en un cajón de la casa familiar, y por ello, la centralidad de quien lo completa es tan pronunciada.

En el texto "Imborrables", Ángela describe con minuciosidad las figuras de los tatuajes que exhibe su cuerpo. Dibujante y performista antes que escritora, la hija de Paco Urondo se expresa por imágenes que se aproximan a verdaderas manifestaciones performáticas. Los tatuajes de motivos naturales y arquetípicos - el agua, especialmente - alcanzan significaciones muy precisas vinculadas a las representaciones de la huérfana. Como ella misma explica en "Imborrables"

Las flores son para mamá; no tengo dónde llevárselas, por eso las llevo conmigo. El agua que fluye es Urondo, por definición. En idioma vasco, Ur-ondo (ur: agua; ondo: junto a) significa lugar donde hay vida en el agua, lugar junto al agua, aguas profundas, aguas buenas, aguas vivas, aquedal. (URONDO RABOY, 2012, p. 220)

Las imágenes visuales, ligadas a su otro modo de expresión, las artes plásticas, son esenciales. Ángela registra la aparición súbita e invasiva de las imágenes en su consciencia, como cuando se refiere a las sensaciones de la infancia sin padres: "A veces como un pantallazo, se me venía una imagen o una sensación de recordarlos, en un aroma, una melodía o un movimiento" (URONDO RABOY, 2012, p. 220).

Las fotografías, siempre escasas, insuficientes y apreciadas generan los comentarios interrogantes de la niña en cuerpo de adulta. Son las que evocan la infancia, puesto que, como observó Bachelard "las imágenes visuales son tan nítidas, forman con tanta naturalidad cuadros que resumen la vida, que tienen el privilegio de fácil evocación en nuestros recuerdos de infancia" (BACHELARD, 1988, p. 119).

Al lado de las imágenes, completando su sentido, Ángela se sumerge en el lenguaje de la militancia política de los padres, de modo semejante a como vimos en La casa de los conejos con la palabra 
"embudo". Uno de los textos que ilustra mejor el trabajo arqueológico sobre el lenguaje de la década del setenta es el poema "Caer no es caer". Una misma estructura paradójica, con el esquema "A no es A" resalta términos (sustantivos o infinitivos en función de sustantivos) con significado propio en la lengua de los padres militantes ("Chupar no es chupar / Cita no es cita / Dar no es dar / caer no es caer"). Veintidós versos del poema reiteran esa estructura, hasta que los dos últimos se vuelve hacia la propia identidad: "Ser no es ser./ Yo, nada." El poema menciona el lenguaje que solo la adulta puede recuperar por algo que no es exactamente el recuerdo de una experiencia. Las palabras son figuraciones de las posibles voces de sus padres.

Uno de los proyectos de Ángela Urondo, que consiste en identificar los escritos de su madre, publicados sin firma en el diario "Noticias", cuando Alicia era responsable por las notas sindicales del diario de los años setenta, puede ser considerada como otra operación centrada en la lengua, de propósito similar al que encontramos en el poema "Caer no es caer". La propia Ángela denomina de arqueológica esa lectura de las notas escritas por la madre "Es un trabajo arqueológico: tratar de desglosar en la sección Gremiales, cuáles fueron las notas que pudo haber escrito mamá. (...) Se trata de encontrar ciertos usos, ciertos rasgos de estilo." (ENRIQUEZ, 2013, p.4) No es por casualidad que el último verso del poema "Caer no es caer" propone la identificación del Yo con la nada. Si tenemos en cuenta la radical orfandad que transmiten los textos de Ángela Urondo Raboy veríamos en esa identificación un modo de reafirmar, en términos figurativos, esa condición.

\section{Consideraciones finales}

Como se dijo muchas veces la infancia es la memoria de la infancia. Ella siempre es textualizada y enunciada por otro, por el adulto. Para recrear la infancia traumática en la Argentina de los años setenta, Laura Alcoba y Ángela Urondo Raboy transitan también por territorios de la fabulación. Sus textos nos proponen un pacto ambiguo, propio de la autofiguración o de la autoficción. Son obras de la memoria, y sin embargo la escritura revela todos los recursos de la ficción y de la intención estética. Para recrear las niñas que fueron, cuentan relatos de infancia. 
Las adultas, dispuestas a trabajar el lenguaje como literatura, inventan las voces de la infancia. Como diría Bachelard, al rememorarla, no pueden evitar que la imaginación y la memoria se fusionen. Memoria e imaginación crean un universo imagético. Retomando el mito del huérfano o del niño desamparado, a partir de la conjunción de la memoria y de la imaginación, comienza el trabajo sobre el lenguaje. Con la intervención en los usos convencionales, comienza la búsqueda arqueológica detrás de los restos, lo que lleva a mostrar aspectos menos convencionales de la memoria.

Las obras instalan la distancia que da cabida a la "memoria insatisfecha". A propósito de esa memoria, hay un texto particularmente significativo en ¿Quién te creés que sos?. Ya al final del libro, en "Señor Orga", la Ángela adulta que todavía vive con sentimiento de orfandad, revela una mirada crítica sobre uno de los antiguos militantes de la organización Montoneros que participa de uno de los tantos actos de la memoria de las últimas décadas: "Como efecto colateral, empiezo a entender la lógica de por qué soy una tipa tan des orga nizada. Al rato, a lo lejos: "Patria o muerte. Venceremos!, concluye efectista Sr. Orga, sacando a relucir antiguos slogans." ( URONDO RABOY, 2012, p. 204)

Ese texto se conecta con el documento de Horacio Verbinsky, reproducido en las primeras páginas, en la cual leemos que "Hablamos de memoria, no de idealización retrospectiva, acrítica. (VERBINSKY apud URONDO RABOY, 2012, p. 26). Para enfrentar "el discurso efectista", "los antiguos slogans", "la idealización acrítica", nada mejor que la visión de quien ve por primera vez el mundo, es decir, de un niño, pero sin ninguna ingenuidad. También es cierto que en los discursos de la memoria la revisión crítica solo fue posible recientemente, para lo cual nos sirven las reflexiones de Andreas Huyssen. En el capítulo titulado "Resistencia à memoria: usos e abusos do esquecimento público", incluido en Culturas do pasado-presente, Huyssen escribe que el olvido público cumple una función. Tomando como un ejemplo el caso de Argentina, afirma que la violencia ejercida por la guerrilla armada de comienzos de la década del setenta "teve de ser "esquecida" (silenciada, desarticulada) para permitir o surgimento de um consenso nacional da memória em torno da figura vitimada dos desaparecidos" (HUYSSEN, 2014, p. 160) La memoria insatisfecha solo pudo ser elaborada después de ese consenso. Los proyectos de Laura Alcoba y de Angela Urondo Raboy pertenecen sin duda a esa memoria personal y política. 


\section{Referencias}

ALCOBA, Laura. La casa de los conejos. Trad. Leopoldo Brizuela. Buenos Aires: Edhasa, 2010.

ARFUCH, Leonor. Crítica cultural entre política y poética. Buenos Aires: Fondo de Cultura, 2008.

ARFUCH, Leonor. Memoria y autobiografía. Exploraciones en los límites. Buenos Aires: Fondo de Cultura, 2013.

BENJAMIN, Walter. Reflexões sobre a criança, o brinquedo e a educação. São Paulo: Duas cidades, 2007.

BACHELARD, Gaston. A poética do devaneio. Trad. Antonio de Pádua Danesi. São Paulo: Martins Fontes, 1988.

BARTHES, Roland. Sade, Fourier, Loiola. Trad. Maria de Santa Cruz. Lisboa: Edições 70, 1971.

BLEJMAR, Jordana. "Ficción o muerte". Autofiguración y testimonio en Diario de una Princesa Montonera - 110\%Verdad". Disponível em: $<\mathrm{http}$ :/criticalatinoamericana.com/ficcion-o-muerte-atufiguracion-ytestimonio-en-diario-de-una-princesa-montonera-110-verdad/> .

DE GRANDIS, R. Reciclaje cultural y memoria revolucionaria. La práctica polémica de José Pablo Feinmann. Buenos Aires: Biblos, 2006.

DELEUZE, Gilles. Abecedario. El abecedario de Gilles Deleuze. Disponível em: <www.youtube. com/watch?V=QWQurpdyF6s $>$.

ENRIQUEZ, M. “Caer no es caer”. Disponível em: $<$ http://www.pagina12. com.ar/ imprimir/diario/suplementos/libros/10-4933-20-04.ht...>.

FORNÉ, Anna. La memoria insatisfecha en La casa de los conejos de Laura Alcoba. Disponível em: <http://bibliotecavirtual.unl.edu.ar:8180/ publicaciones/bitstream/1185/1185/3762/1/HF_8_10pag65_74pdf $>$.

HUYSSEN, Andreas. Culturas do passado-presente. Modernismos, artes visuais, políticas da memória. Trad. Vera Ribeiro. Rio de Janeiro: Contraponto, 2014.

PELLER, Mariela. La mirada de la niña. Sobre La casa de los conejos de Laura Alcoba. Disponível em: <http://perio.unlp.edu.ar/ojs/indec.php/ question/article/viewarticle/796>. 
PRADELLI, Ángela. Em mi nombre. Historias de identidades restituidas. Buenos Aires: Paidós, 2014.

SARLO, Beatriz. Tiempo pasado. Cultura de la memoria y giro subjetivo. Una discusión. Buenos Aires: Siglo veintiuno, 2012.

URONDO RABOY, Ángela. ¿Quién te creés que sos?. Buenos Aires: Capital intelectual, 2012. 